\title{
Low-dose vasopressin infusion results in increased mortality and cardiac dysfunction following ischemia-reperfusion injury in mice
} Toonchai Indrambarya, John H Boyd, Yingjin Wang, Melissa McConechy and Keith R Walley

\author{
Critical Care Research Laboratories, Heart + Lung Institute, University of British Columbia, 166 - 1081 Burrard Street, Vancouver, British Columbia, \\ V6Z 1Y6, Canada \\ Corresponding author: John H Boyd, jboyd@mrl.ubc.ca
}

Received: 5 Mar 2009 Revisions requested: 31 Mar 2009 Revisions received: 2 Jun 2009 Accepted: 23 Jun 2009 Published: 23 Jun 2009

Critical Care 2009, 13:R98 (doi:10.1186/cc7930)

This article is online at: http://ccforum.com/content/13/3/R98

(C) 2009 Indrambarya et al.; licensee BioMed Central Ltd.

This is an open access article distributed under the terms of the Creative Commons Attribution License (http://creativecommons.org/licenses/by/2.0), which permits unrestricted use, distribution, and reproduction in any medium, provided the original work is properly cited.

\begin{abstract}
Introduction Arginine vasopressin is a vasoactive drug commonly used in distributive shock states including mixed shock with a cardiac component. However, the direct effect of arginine vasopressin on the function of the ischemia/reperfusion injured heart has not been clearly elucidated.

Methods We measured left ventricular ejection fraction using trans-thoracic echocardiography in C57B6 mice, both in normal controls and following ischemia/reperfusion injury induced by a one hour ligation of the left anterior descending coronary artery. Mice were treated with one of normal saline, dobutamine (8.33 $\mu \mathrm{g} / \mathrm{kg} / \mathrm{min}$ ), or arginine vasopressin (0.00057 Units $/ \mathrm{kg} / \mathrm{min}$, equivalent to 0.04 Units $/ \mathrm{min}$ in a $70 \mathrm{~kg}$ human) delivered by an intraperitoneal micro-osmotic pump. Arterial blood pressure was measured using a micromanometer catheter. In addition, mortality was recorded and cardiac tissues processed for RNA and protein.
\end{abstract}

Results Baseline left ventricular ejection fraction was $65.6 \%$ (60 to 72). In normal control mice, there was no difference in left ventricular ejection fraction according to infusion group. Following ischemia/reperfusion injury, AVP treatment significantly reduced day 1 left ventricular ejection fraction $46.2 \%$ (34.4 to 52.0), both in comparison with baseline and day 1 saline treated controls $56.9 \%$ (42.4 to 60.2 ). There were no significant differences in preload (left ventricular end diastolic volume), afterload (blood pressure) or heart rate to account for the effect of AVP on left ventricular ejection fraction. The sevenday mortality rate was highest in the arginine vasopressin group. Following ischemia/reperfusion injury, we found no change in cardiac V1 Receptor expression but a $40 \%$ decrease in Oxytocin Receptor expression.

Conclusions Arginine vasopressin infusion significantly depressed the myocardial function in an ischemia/reperfusion model and increased mortality in comparison with both saline and dobutamine treated animals. The use of vasopressin may be contraindicated in non-vasodilatory shock states associated with significant cardiac injury.

\section{Introduction}

With the increasing medical complexity of the critically ill, shock due to a combination of vasodilation and cardiac dysfunction is increasingly frequent. Two common clinical examples of this are first, vasodilation following cardiopulmonary bypass surgery and, second, the cardiac dysfunction during septic shock. These mixed shock conditions are routinely treated with intravenous fluids plus inotropes combined with a vasopressor such as norepinephrine or arginine vasopressin (AVP). AVP is a vasopressor commonly used in intensive care units and cardiac surgical units due to its efficacy in restorating blood pressure [1-6]. The effects of AVP are mediated via vasopressin 1 receptors (V1R; predominantly vascular), vasopressin 2 receptors (V2R; predominantly renal), vasopressin 3 receptors (V3R; predominantly central), and the oxytocin receptors (OTR) [7]. In addition, vasopressin blocks $\mathrm{K}_{\text {ATP }}$ channels [8] and potentiates the effect of adrenergic agents [9]. Vascular V1R appear to mediate the majority of effects of vasopressin in reversing vasoplegia and catecholamine tolerance $[4,10]$.

ANOVA: analysis of variance; AVP: arginine vasopressin; DOB: dobutamine; l/R: ischemia/reperfusion; LAD: left anterior descending coronary artery; LVEF: left ventricular ejection fraction; LVEDV: left ventricular end diastolic volume; OTR: oxytocin receptors; P2R: purinergic receptors; RT-PCR: real-time polymerase chain reaction; SL: normal saline solution; V1R: vasopressin 1 receptor; V2R: vasopressin 2 receptor; V3R: vasopressin 3 receptor. 
In healthy individuals, AVP administration at low doses $(<0.04$ Units/minute) has little effect on blood pressure. However, there are multiple reports of increased blood pressure responsiveness to low-dose AVP in both septic shock and distributive shock after cardiopulmonary bypass surgery [7,11]. Consequently, low-dose AVP has been increasingly used to treat these disorders [1-3,12-17].

Despite its widespread use, there remains considerable uncertainty regarding its cardiac effects. When studied at the high doses ( 0.1 to 1 Unit/minute) previously used for mesenteric vessel constriction in gastrointestinal bleeding [18], deleterious effects of AVP on myocardial performance were reported including coronary vasospasm [19-21]. At these high doses, AVP may also impair indices of ventricular contraction and relaxation without overt global ischemia [22]. In addition, the baroreflex mediated via V1R might cause bradycardia and direct cardiac suppression [23,24]. Although the most highly expressed vasopressin receptor in the heart is $\mathrm{V} 1 \mathrm{R}$, the other receptors are physiologically active. Gene transfer of $\mathrm{V} 2 \mathrm{R}$ into failing myocardium increases cardiac contractility $[25,26]$, while OTR mediates a calcium-dependent vasodilatory response via stimulation of the nitric oxide pathway in endothelial cells [27]. OTR stimulation also results in release of atrial natriuretic peptide from the heart $[28,29]$.

Clinically, there are conflicting reports on the effect of AVP on cardiac function. In some series, AVP infusion has been reported to decrease cardiac output [28,30,31]. Others have observed a dramatic restoration of blood pressure without a decrease in stroke volume or other measures of cardiac function $[2,30,32,33]$. The clinical observation that AVP increases mean arterial pressure in patients with shock is uniform across these studies, so interpreting any direct effect on myocardial contractility must be done with caution as alterations in afterload have a significant impact on measures of cardiac performance.

The uncertainty as to the in vivo action of AVP on the heart provides the rationale for this study. Further, as the use of AVP moves into the mainstream $[1,12]$, it is important to understand its cardiac effects both on the normal heart and in the injured or ischemic heart. We chose a model of subacute heart failure without overt shock as the direct in vivo effects of AVP on contractility are extremely difficult to distinguish from indirect effects due to changes in afterload (blood pressure). In this study, we used a mouse model of ischemia/reperfusion (I/R) induced heart failure to compare the effect of continuous infusion of AVP with saline control (SL) or standard inotropic therapy (dobutamine (DOB)) on cardiac function in mice. We assessed cardiac function using trans-thoracic echocardiography, and in parallel experiments used intra-arterial pressure measurements to determine whether cardiac function was influenced by changes in systemic blood pressure.

\section{Materials and methods}

These experiments were approved by the UBC Animal Care Committee and conform to Canadian and National Institutes of Health guidelines regarding animal experimentation. All experiments were conducted in 10- to 14-week-old male C57B6 mice as a control and in mice following $\mathrm{I} / \mathrm{R}$ injury induced by one hour ligation of the left anterior descending coronary artery (LAD; see below). Intraperitoneal pumps ( $1 \mu \mathrm{L} /$ hour for 72 hours, Alzet micro-osmotic pump, Alza Corporation, Palo Alto, CA, USA) delivered normal saline (SL control), DOB at $8.33 \mu \mathrm{g} / \mathrm{kg} / \mathrm{minute}$, or arginine vasopressin at 0.00057 Units/ $\mathrm{kg} /$ minute (equivalent to 0.04 Units/minute in a $70 \mathrm{~kg}$ human; AVP treatment). AVP levels in rodents and humans are similar, while in rodents the intraperitoneal route of administration for AVP increases plasma AVP levels in a manner very similar to intravenous dosing in humans [34,35]. At least five mice per time point in each group were studied.

\section{Ischemia-reperfusion of the LAD}

An open-chest model of I/R using ligation and reperfusion of the LAD was modified from Michael and colleagues [36]. Mice were anesthetized using ketamine $(75 \mathrm{mg} / \mathrm{kg})$ and xylazine (10 $\mathrm{mg} / \mathrm{kg}$ ) in order to facilitate endotracheal intubation using a 22 Gauge catheter. Thereafter, deep anesthesia was maintained with 1 to $2 \%$ isoflurane. Ventilation was controlled using Mouse Ventilator (Model 687, Harvard Instruments, Holiston, MA, USA) with a tidal volume of $0.5 \mathrm{~mL}$ and a respiratory rate of 120 breaths/minute. After a left thoracotomy was performed at the level of the second or third intercostal space, the LAD was identified and a 6-0 polypropylene suture was placed around the LAD. Occlusion of the LAD was accomplished by pulling the suture ends through a small piece of PE-50 tubing and occlusion was confirmed by discoloration of the anterior left ventricle wall.

Following one hour of ischemia the ligature was released to allow reperfusion, which was visualized. Following the thoracotomy wound closure, the intraperitoneal pump (see above) was implanted into the peritoneal cavity. Intra-operatively, $1 \mathrm{~mL}$ of normal saline was injected subcutaneously for volume resuscitation and subcutaneous buprenorphrine for pain control were given. After recovery and resumption of spontaneous ventilation, mice were extubated.

\section{Myocardial function evaluation}

Left ventricular ejection fraction (LVEF) was used to measure cardiac function at baseline, day 1 and day 3 post I/R. Transthoracic echocardiography using a Vevo 770 cardiac ultrasound (Visualsonics, Toronto, Canada) while anesthetized with 1 to $2 \%$ inhaled isofluorane. Left ventricular internal diameter at end-systole and end-diastole from Short Axis 2D views at the level of the papillary muscles were identified and used for measurement of LVEF using the manufacturer's software. All echocardiographs were performed by the same qualified 
investigator ( $\mathrm{TI})$, and quality control was ensured by the other investigator (JB) blinded from treatment group.

\section{Direct blood pressure measurement}

As arterial catheterization is a terminal procedure, separate mice were anesthetized in the same way and a number 2 French micromanometer catheter (Mikro-tip SPR-838, Millar Instruments Inc., Houston, TX, USA) was advanced via the carotid artery into the ascending aorta to measure blood pressure. The heart was excised, frozen in liquid nitrogen, and stored at $-80^{\circ} \mathrm{C}$ for subsequent study.

\section{Quantitative real-time PCR}

Total RNA was extracted from frozen heart samples using Trizol (Invitrogen, Carlsbad, CA, USA) as per the manufacturer's instructions. RNA was obtained from either I/R injured hearts or control, non-injured heart. RNA $1 \mu \mathrm{g}$ was treated with DNAse I Amplification Grade (Invitrogen, Carlsbad, CA, USA) and the product underwent quantitiative RT-PCR using MMLV RT (Invitrogen, Carlsbad, CA, USA) followed by PCR amplification with Taq DNA Polymerase (Qiagen, Valencia, CA, USA). PCR was 40 cycles at $94^{\circ} \mathrm{C}$ for 15 seconds, $58^{\circ} \mathrm{C}$ for 30 seconds, and $72^{\circ} \mathrm{C}$ for 30 seconds. Primers were as follows, V1R forward; TCGTCCAGATGTGGTCAGTC, V1R reverse; AGCTGTTCAAGG-AAGCCAGT, V2R forward; CCTGGTGTCTACCACGTCTG, V2R reverse; GGTCTCGGTCATCCAGTAGC. OTR Forward; AGGAGCTGTTCTCAACCATC OTR Reverse; OPCR TGCAAACCAATCAATAGGCAC. SYBER green was used as the fluorescence indicator, which represented quantity of amplicon production with PCR cycle (Ct value). All quantitative RT-PCR reactions were run in triplicate and an average $\mathrm{Ct}$ value was calculated for each PCR condition. Fold change of Ct value of each sample was calculate using glyceraldehyde3-phosphate dehydrogenase (GAPDH) as a background control.

\section{Western blot for OTR}

A $20 \mu \mathrm{g}$ sample of each protein was mixed with equal volumes of SDS reducing buffer $(62.5 \mathrm{mmol}$ Tris $\mathrm{I}-1, \mathrm{pH} 6.8,2 \%(\mathrm{w} / \mathrm{v})$ SDS, $10 \%(\mathrm{v} / \mathrm{v})$ glycerol, $100 \mathrm{mmol}$ dithiothreitol I-1, 0.05\% $(\mathrm{w} / \mathrm{v})$ bromophenol blue) and incubated in a boiling waterbath for five minutes before loading. Using the discontinuous buffer system SDS-PAGE, proteins were separated according to size on $10 \%$ polyacrylamide gels and electroblotted on to nitrocellulose membranes. After blocking non-specific antigens with $5 \%(\mathrm{w} / \mathrm{v})$ skim milk for one hour, western blots were probed with rabbit's anti-OTR immunoglobulin (Santa Cruz Biotechnology, California, USA), dilute 1:2000 in 5\% (w/v) BSA and Tris-Buffered Saline Tween-20 at $4^{\circ} \mathrm{C}$ overnight. Using the Enzymatic Chemiluminescence (ECL, Amersham ${ }^{\mathrm{TM}}$, GE Healthcare, Buckinghamshire, UK) assay, anti-rabbit horseradish peroxidase molecule bound goat immunoglobulin was used as secondary antibody. The images of ECL reaction were obtained using Chemigenius2 with CCD camera (Syn- gene, Cambridge, UK). The densitometry was performed using imageJ 1.410 (National Institutes of Health, Maryland, USA).

\section{Data analysis}

All graphical values are expressed as means \pm standard error of the mean, and to provide more descriptive data in the results section we present data as median (inter-quartile range). In the case of unequal variance, groups were analyzed using KruskalWallis one-way analysis of variance (ANOVA) on Ranks and subsequent multiple comparisons were performed using Dunn's Method. In groups with equal variance one-way ANOVA determined if differences existed, then pairwise multiple comparison procedures used the Holm-Sidak method. The analyses were performed using Sigmastat (SPSS, Chicago, IL, USA), and statistical significance was set at $P<0.05$. Kaplan Meier survival was used to demonstrate the survival rate of each treatment group, and log rank test was used to test for differences between groups.

\section{Results}

Vasopressin significantly reduces left ventricular ejection fraction following $I / R$ but has no effect in intact mice

The baseline (normal) LVEF obtained from 2D short axis Mmode left ventricular internal diameter trace was $65.6 \%$ (60 to $72 ; n=29$ ). In mice ( $n=4$ per group) who received intraperitoneal infusions but were not subjected to I/R of the LAD, there was no statistically significant difference in LVEF between SL controls at $62.7 \%$ (56.9 to 62.5 ), DOB $72.94 \%$ (73.9 to 56.0), and AVP treatment 54.73\% (52.1 to 57.3). In mice subjected to I/R injury, AVP treatment significantly reduced day 1 LVEF to $46.2 \%$ (34.4 to 52.0) in comparison with both baseline and with day $1 \mathrm{SL}$ control $56.9 \%$ (42.4 to 60.2 ), while DOB-treated mice did not demonstrate a significant reduction in day 1 LVEF compared with baseline $53.7 \%$ (47.0 to 61.7), as shown in Figure 1. In comparison to day 1, LVEF measured at day 3 demonstrated improvements in all groups; however, mice receiving AVP remained significantly lower than baseline.

\section{The decreased LVEF in vasopressin treated mice is due to altered contractility rather than through influencing heart rate, preload or afterload}

Baseline heart rate was similar in AVP, SL, and DOB groups respectively, with no statistically significant differences between groups. Following I/R of the LAD there was no statistical difference between groups at days 1 and 3 (Table 1). To assess left ventricular preload, we measured left ventricular end diastolic volume (LVEDV) using transthoracic echocardiography. Although there was a trend towards decreased LVEDV at day 1 and day 3 in all groups compared with their respective baseline values, there was no significant difference between AVP, SL, and DOB-treated mice at day 1 or day 3 after I/R (Table 1). Afterload was assessed through invasive 
Figure 1

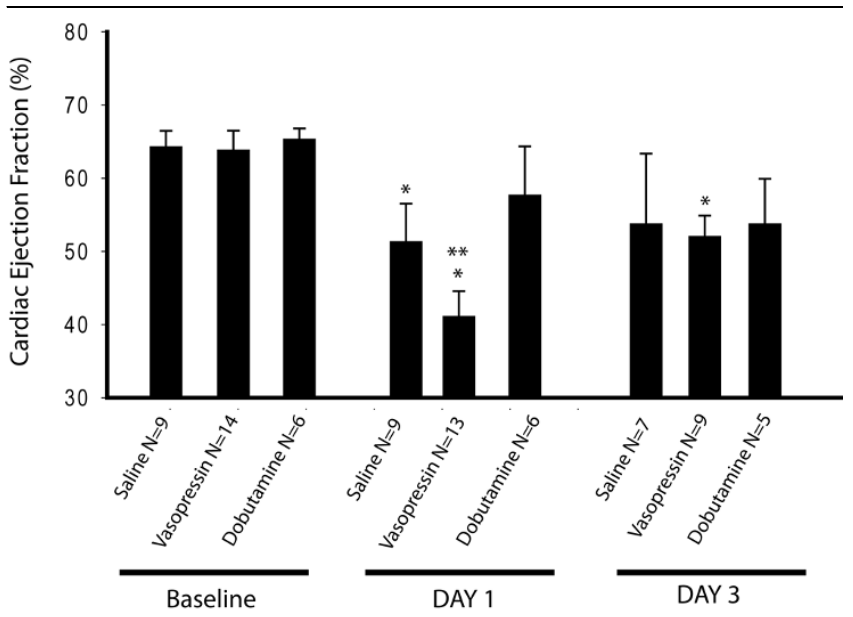

Cardiac function as assessed by $2 \mathrm{D} \mathrm{ECHO}$ at baseline and following I/ $\mathrm{R}$ of the LAD. The baseline (normal) left ventricular ejection fraction (LVEF) obtained from 2D short axis M-mode left ventricular internal diameter trace was $67.52 \pm 1.8 \%, 63.48 \pm 2.9 \%$, and $65.47 \pm 2.4 \%$ in arginine vasopressin (AVP; $n=14)$, normal saline solution (SL; $n=9$ ), and dobutamine (DOB; $n=6$ ), resepctively. Following ischemia/reperfusion (I/R) injury, AVP treatment significantly reduced day $1 \mathrm{LVEF}$ $(41.1 \pm 3.4 \%)$ in comparison with SL control $(51.6 \pm 4.3 \%)$, while both group had significant reductions in LVEF vs baseline. DOB mitigated the decrease in LVEF $(57.7 \pm 6.7 \%)$ day 1 post l/R. LVEF measured at day 3 demonstrated improvement in all groups; however, mice receiving AVP remained significantly lower than baseline. ${ }^{*} P<0.05$ vs baseline, ${ }^{\star \star} P<0.05$ vs SL-treated mice. Results are present as means \pm standard error of the mean. $L A D=$ left anterior descending coronary artery.

measurement of systolic blood pressure, diastolic blood pressure, and mean arterial pressure are shown in Figure 2. Although there was no statistically significant differences in blood pressure, mean arterial pressure trended to lowest in AVP group with a mean arterial pressure of $91.1 \mathrm{mmHg}(88.2$ to 98.6 ) compared with $104.3 \mathrm{mmHg}$ (91.6 to 110.1) in DOB and $95.9 \mathrm{mmHg}$ (90.8 to 99.8 ) in SL controls.

\section{Vasopressin infusion results in higher mortality following I/R of the LAD than saline or dobutamine}

When compared with infusions of either saline or DOB, vasopressin results in dramatically increased mortality (Figure 3). This difference begins as soon as day 1 following I/R and persists throughout our seven-day observation period. The mice were no different in appearance (grooming, temperature, activity level) according to infusion group, and in general appeared healthy during routine monitoring.

\section{Only V1R and OTR are expressed in the heart, I/R of the LAD results in changes in expression of OTR}

Vasopressin has minimal effects on cardiac performance in intact animals, while I/R injury results in a dramatic suppression in cardiac ejection fraction when compared with saline infusion. We therefore verified whether this might be due to regulation of vasopressin receptor subtype in the heart as a result of I/R. Expression of V1R, V2R, and OTR in the heart was assessed in four mice per group at baseline and at day 1 following I/R of the LAD. Using RT-PCR, we found that normal hearts express only V1R and OTR, while V2R is not detectable. There was no change in V1R expression as a result of I/R injury, while OTR expression was reduced by $40 \%$ compared with controls (Figure 4).

\section{Discussion}

The major finding of this study is that although continuous infusion of low-dose AVP (equivalent to 0.04 Units/minute in an average human) had no effect on hemodynamics or cardiac function in the resting state, following one hour of LAD I/R, AVP had a negative inotropic effect and seemed to increase early mortality. As previous studies have noted, AVP may exert cardiac suppressive effects through a variety of mechanisms [22-24,30,31], therefore, we went on to identify a potential mechanism behind this ischemia-induced cardiac sensitization to vasopressin.

Vasopressin is a peptide produced by the hypothalamus. Its effects are mediated through at least five specific receptors V1R, V2R, V3R, OTR, and purinergic receptors (P2R) $[4,10]$. $\mathrm{V} 1 \mathrm{R}$ is the receptor thought to be primarily responsible for

Table 1

Baseline, day 1 and day 3 heart rate and left ventricular end diastolic volume post I/R injury and intraperitoneal pump implantation

\begin{tabular}{|c|c|c|c|c|}
\hline Group & Parameter & Baseline & Day 1 post I/R & Day 3 post I/R \\
\hline $\begin{array}{c}\text { Vasopressin } \\
n=14\end{array}$ & $\begin{array}{l}\text { HR (bpm): } \\
\text { LVEDV (uL): }\end{array}$ & $\begin{array}{c}495 \pm 18.1 \\
67 \pm 5\end{array}$ & $\begin{array}{c}517.15 \pm 15.67 \\
58 \pm 8\end{array}$ & $\begin{array}{c}485.11 \pm 34.94 \\
60 \pm 9\end{array}$ \\
\hline $\begin{array}{l}\text { Dobutamine } \\
\qquad n=6\end{array}$ & $\begin{array}{l}\text { HR (bpm): } \\
\text { LVEDV (uL): }\end{array}$ & $\begin{array}{c}439 \pm 28.7 \\
64 \pm 7\end{array}$ & $\begin{array}{c}475.17 \pm 32.35 \\
55 \pm 7\end{array}$ & $\begin{array}{c}507.1 \pm 50.68 \\
55 \pm 7\end{array}$ \\
\hline $\begin{array}{c}\text { Normal Saline } \\
n=9\end{array}$ & $\begin{array}{l}\text { HR (bpm): } \\
\text { LVEDV (uL): }\end{array}$ & $\begin{array}{c}448 \pm 15.1 \\
69 \pm 4\end{array}$ & $\begin{array}{c}486.66 \pm 16.29 \\
60 \pm 6\end{array}$ & $\begin{array}{c}438 \pm 32.10 \\
58 \pm 6\end{array}$ \\
\hline
\end{tabular}

Heart rate (HR) was determined using limb lead echocardiography pads during echocardiogram, while left ventricular end diastolic volume (LVEDV) was determined using echocardiography. No significant differences in HR or LVEDV exist between groups infused with saline $(n=9)$ dobutamine $(n=6)$, or vasopressin $(n=14)$. Results are present as means \pm standard error of the mean. I/R $=$ ischemia/reperfusion. 
Figure 2

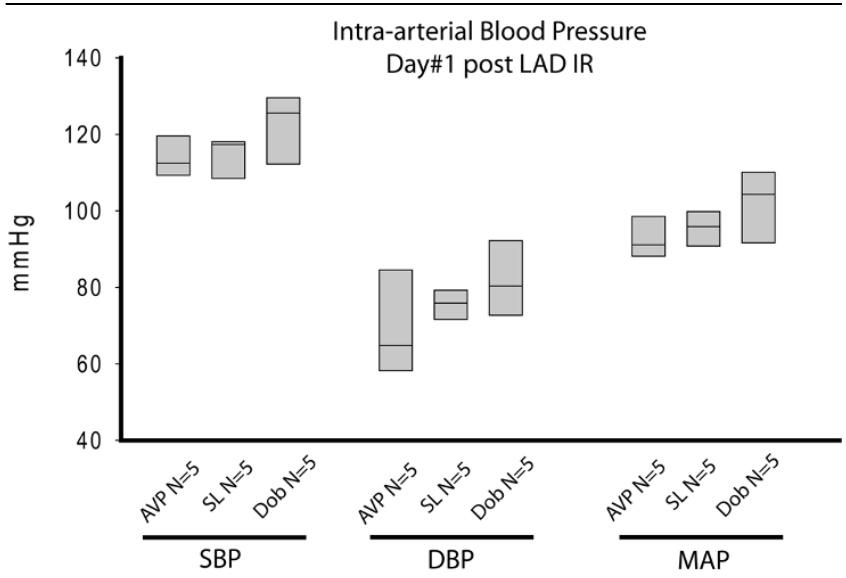

Intra-arterial blood pressure at day 1 following I/R of the LAD. Systolic blood pressure (SBP), diastolic blood pressure (DBP), and mean arterial pressure (MAP) are shown. Although there was no statistically significant differences in blood pressure, MAP trended to lowest in arginine vasopressin (AVP) group $(n=5)$ with a MAP of $89.7 \pm 1.7$ $\mathrm{mmHg}$ compared with $100.1 \pm 6.0$ in dobutamine $(\mathrm{DOB} ; \mathrm{n}=5)$ and $94.8 \pm 3.4$ in normal saline solution $(S L)$ control $(n=5)$. Results are present as means \pm standard error of the mean. $I / R=$ ischemia/reperfusion; $L A D=$ left anterior descending coronary artery.

increased vascular tone because it mediates vasoconstriction in vascular smooth muscle. It has also been found to be expressed on cardiac myocytes and the kidney. V2Rs are found mainly in the renal collecting duct and are responsible for the antidiuretic effect of vasopressin. OTRs are found diffusely throughout the body and are thought to mediate vasodilation. Thus vasopressin is able to cause either vasoconstriction or vasodilation depending on the tissue specific distribution of V1R vs OTR and is able to enhance the

\section{Figure 3}

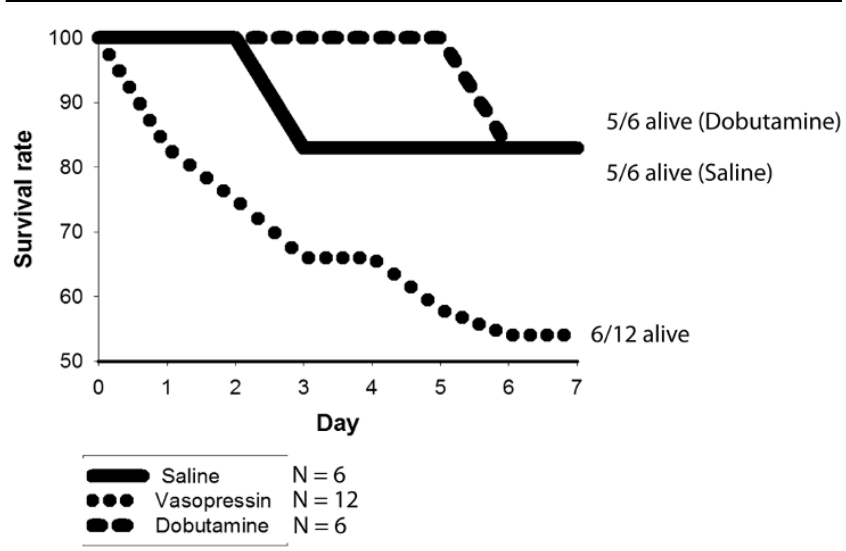

Kaplan Meier survival curve for mice in the three treatment groups. When compared with infusions of either saline $(n=6)$ or dobutamine $(n$ $=6)$, vasopressin $(n=12)$ results in dramatically increased mortality. This difference begins as soon as day 1 following ischemia/reperfusion and persists throughout our seven day observation period.
Figure 4

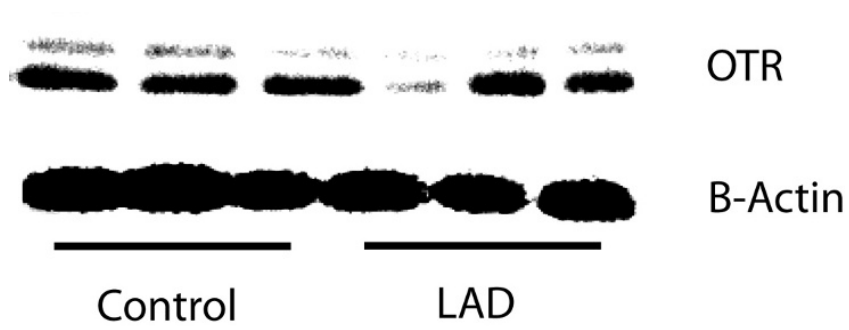

Western blot of left ventricular OTR levels at baseline and day 1 following I/R of the LAD. Left ventricular tissue was dissected and flash frozen for protein extraction both in control (baseline) animals and at day 1 following ischemia/reperfusion (I/R) of the left anterior descending coronary artery (LAD). We chose this timepoint as the enhanced physiologic effect (cardiac suppression) was observed by day 1. In those animals subjected to $\mathrm{l} / \mathrm{R}$ of the LAD, oxytocin receptor (OTR) expression normalized to $\beta$-actin was reduced by $40 \%$ compared with controls.

effect of vasoconstrictor agents such as norepinephrine through mechanisms yet to be identified [9].

Although its mechanism of action on the vasculature is well understood, vasopressin has dose-dependent effects on both cardiac contractility and coronary arterial tone. It appears that at low doses vasopressin may act mainly through the P2R with a shifting of physiologic effect from coronary smooth muscle V1R-mediated vasoconstriction to P2R-mediated vascular endothelial vasodilation. At higher doses this relation is reversed with V1R-mediated coronary arterial vasoconstriction predominating, with a resultant drop in cardiac output. Due to safety concerns at higher doses, most clinical data relating to direct cardiac effects are using low doses of vasopressin $(\leq$ 0.04 Units/minute), often in conjunction with inotropes. Patients with vasodilatory shock increase systemic vascular resistance twofold, while only diminishing cardiac output by $14 \%$ in response to vasopressin - indirect evidence of some positive inotropy [37]. Similarly, when co-infused with the phosphodiesterase inhibitor milrinone in patients with advanced heart failure, vasopressin resulted in increased vascular tone and blood pressure with no resultant change in cardiac output [38]. In hypotensive post-cardiotomy patients who remain in shock despite catecholamine infusions, the addition of low-dose vasopressin resulted in a significant increase in left ventricular work index and a decrease in vasopressor use, inotrope usage, and heart rate [2]. It is of great interest to the clinician that the hemodynamic effects of vasopressin are potentiated by the shock state, because in normal subjects vasoconstriction only occurs at high doses, while fluid unresponsive shock confers a powerful vasopressor effect at low doses. This may reflect an acute depletion of circulating vasopressin with subsequent hypersensitivity to its effects [37,39]. Because of these theoretical and practical benefits, vasopressin has come into widespread use for shock states, including shock in which myocardial injury plays a contributive 
role [1-3,12-17]. However, the cardiovascular effect of vasopressin on the injured myocardium has yet to be elucidated.

In this study we found that low-dose vasopressin did not significantly alter arterial blood pressure or cardiac ejection fraction in the uninjured state. This experimental observation correlates with the clinical finding that normotensive patients do not exhibit a physiologic response to low-dose vasopressin [37,39]. In contrast, we found AVP significantly decreased LVEF in a model of ischemia reperfusion. Our model used one hour of LAD ischemia and reproducibly depressed day 1 cardiac ejection fraction by approximately $13 \%$ in mice treated with saline infusions (control animals). We compared these saline-infused mice with the standard drug used for cardiogenic shock (DOB) and noted a significant increase in cardiac ejection fraction. This served as both a positive control to assure good absorption of the intra-peritoneal medication as well as a standard of care arm with which to compare cardiac function and mortality. Vasopressin, on the other hand, demonstrated a markedly different effect following LAD I/R than in the intact animal. During the infusion the mean cardiac ejection fraction dropped by $10 \%$ when compared with saline, and by $24 \%$ compared with baseline. This decrease in cardiac contractility appeared to be through a direct cardiac effect as there was no significant change in either preload (LVEDV) or afterload (arterial blood pressure) due to vasopressin.

Vasopressin had no significant effect on cardiac function in intact mice, while following I/R injury vasopressin was cardiosuppressive. We speculated that this may have resulted from alterations in vasopressin receptor expression as a result of I/ $R$. We found that V1R and OTR were expressed in the heart, while V2R was not detectable. V1R expression was not altered as a result of I/R, while OTR expression was reduced by $40 \%$ (Figure 4 ). This stable expression of $\mathrm{V} 1 \mathrm{R}$ combined with decreased OTR expression could result in predominant vasoconstriction in the injured heart, potentially worsening cardiac ischemia and resulting in dysfunction.

In addition to a decline in cardiac contractility, vasopressin resulted in a marked increase in early mortality compared with both saline and DOB-treated mice. The moderate reduction in cardiac ejection fraction and non-statistically significant trend towards a $5 \mathrm{mmHg}$ decrease in blood pressure in the vasopressin-infused group essentially excludes cardiogenic shock as a cause of the excess mortality. Further support for this comes from routine monitoring of the post-operative appearance (grooming, temperature, activity level), with all groups appearing healthy with no evidence of general medical deterioration as would be expected with cardiac insufficiency. Vasopressin and its analogue terlipressin have been reported to induce cardiac arrhythmia (bradycardia and Torsade de Pointes) not associated with clear evidence of myocardial infarction [40-45]. Given the generally healthy clinical condition of the mice, we speculate that the majority of deaths may have related to sudden cardiac events (arrhythmia). How might this occur? Vasopressin has been found to block $\mathrm{K}_{\mathrm{ATP}}$ channels in the vascular endothelium, where this reverses vasoplegia in the systemic circulation [8], but may contribute to sudden vasospasm in the coronary circulation [46]. $\mathrm{K}_{\text {ATP }}$ channels expressed on cardiomyocytes are thought to decrease membrane excitability when activated through stress and thus may be key mediators of ischemic tolerance [46]. Increased membrane excitability as a result of vasopressin acting to close $\mathrm{K}_{\mathrm{ATP}}$ channels could increase the risk of arrhythmia.

Limitations of this study include a lack of continuous cardiac and hemodynamic monitoring. Transient changes in afterload may have influenced the extent of ischemic cardiac damage but may not have been detected by our single measurement, while a lack of continuous cardiac rhythm monitoring did not allow us to determine whether arrhythmia was in fact the major cause of death. Other limitations were the lack of quantification of ischemic myocardium as a result of the $\mathrm{I} / \mathrm{R}$, and that we used whole left ventricular tissue rather than isolated cardiomyocyte digestion, and were thus not able to assess from which cell type the vasopressin receptors were derived. Therefore, the down-regulation of OTR must be regarded as hypothesis generating rather than a proof of mechanism.

In summary, we found that low-dose vasopressin infusion had no significant cardiovascular effect in normal mice. In contrast, following ischemic injury to the myocardium vasopressin exerted a strong negative inotropic effect on the heart, resulting in a significant decline in cardiac ejection fraction as measured by echocardiogram. This decline was not mediated through changes in left ventricular preload or afterload at the time point assayed and the possibility of a direct cardiac effect is raised. We speculate that I/R, by decreasing OTR expression in the heart, may result in vasopressin-inducing vasoconstriction and cardiac dysfunction in the injured heart.

\section{Conclusions}

AVP infusion significantly depressed the myocardial function in I/R injured model and increased the mortality rate in comparison with SL and DOB. The use of vasopressin may be associated with cardiac suppression in non-vasodilatory shock states involving significant cardiac injury.

\section{Key messages}

- Vasopressin infusion decreases cardiac ejection fraction and increases mortality after I/R injury.

- The decrease in cardiac ejection fraction is not caused by an increase in afterload, but rather through a decrease in cardiac contractility.

- Vasopressin should be used with caution in patients who may have a cardiac component contributing to their shock. 


\section{Competing interests}

The authors declare that they have no competing interests.

\section{Authors' contributions}

TI drafted the manuscript, performed echocardiography and molecular experiments, and assisted with animal experiments. JB designed the experiments, wrote the manuscript and performed echocardiography. YW performed animal experiments. MM performed molecular experiments. KW designed the experiments and wrote the manuscript. All authors read and approved the final manuscript.

\section{Acknowledgements}

This project was funded by Canadian Institutes of Health Research (ClHR), Heart and Stroke Foundation and Providence Health Care Research Institute. $\mathrm{KW}$ is a Michael Smith Foundation for Health Research Distinguished Scholar. JB is a Providence Health Care Research Institute Physician Scholar. TI is a Faculty of Medicine, Chulalongkorn University Scholar.

\section{References}

1. Russell JA, Walley KR, Singer J, Gordon AC, Hebert PC, Cooper DJ, Holmes CL, Mehta S, Granton JT, Storms MM, Cook DJ, Presneill JJ, Ayers D: Vasopressin versus norepinephrine infusion in patients with septic shock. N Engl J Med 2008, 358:877-887.

2. Dunser MW, Mayr AJ, Stallinger A, Ulmer H, Ritsch N, Knotzer H, Pajk W, Mutz NJ, Hasibeder WR: Cardiac performance during vasopressin infusion in postcardiotomy shock. Intensive Care Med 2002, 28:746-751.

3. Patel BM, Chittock DR, Russell JA, Walley KR: Beneficial effects of short-term vasopressin infusion during severe septic shock. Anesthesiology 2002, 96:576-582.

4. Holmes CL, Landry DW, Granton JT: Science review: Vasopressin and the cardiovascular system part 1 - receptor physiology. Crit Care 2003, 7:427-434.

5. Dunser MW, Mayr AJ, Ulmer H, Ritsch N, Knotzer H, Pajk W, Luckner G, Mutz NJ, Hasibeder WR: The effects of vasopressin on systemic hemodynamics in catecholamine-resistant septic and postcardiotomy shock: a retrospective analysis. Anesth Analg 2001, 93:7-13.

6. Gold JA, Cullinane S, Chen J, Oz MC, Oliver JA, Landry DW: Vasopressin as an alternative to norepinephrine in the treatment of milrinone-induced hypotension. Crit Care Med 2000, 28:249-252.

7. Holmes CL, Patel BM, Russell JA, Walley KR: Physiology of vasopressin relevant to management of septic shock. Chest 2001, 120:989-1002.

8. Landry DW, Oliver JA: The ATP-sensitive K+ channel mediates hypotension in endotoxemia and hypoxic lactic acidosis in dog. J Clin Invest 1992, 89:2071-2074.

9. Noguera I, Medina P, Segarra G, Martinez MC, Aldasoro M, Vila $\mathrm{JM}$, Lluch S: Potentiation by vasopressin of adrenergic vasoconstriction in the rat isolated mesenteric artery. $\mathrm{Br} J$ Pharmacol 1997, 122:431-438.

10. Holmes CL, Landry DW, Granton JT: Science Review: Vasopressin and the cardiovascular system part 2 - clinical physiology. Crit Care 2004, 8:15-23.

11. Landry DW, Levin HR, Gallant EM, Seo S, D'Alessandro D, Oz MC, Oliver JA: Vasopressin pressor hypersensitivity in vasodilatory septic shock. Crit Care Med 1997, 25:1279-1282.

12. Dellinger RP, Levy MM, Carlet JM, Bion J, Parker MM, Jaeschke R, Reinhart K, Angus DC, Brun-Buisson C, Beale R, Calandra T, Dhainaut JF, Gerlach H, Harvey M, Marini JJ, Marshall J, Ranieri M, Ramsay G, Sevransky J, Thompson BT, Townsend S, Vender JS, Zimmerman JL, Vincent JL: Surviving Sepsis Campaign: International guidelines for management of severe sepsis and septic shock: 2008. Crit Care Med 2008, 36:296-327.

13. Lange M, Ertmer $C$, Westphal M: Vasopressin vs. terlipressinin the treatment of cardiovascular failure in sepsis. Intensive Care Med 2008, 34:821-832.
14. Albanese J, Leone M, Delmas A, Martin C: Terlipressin or norepinephrine in hyperdynamic septic shock: a prospective, randomized study. Crit Care Med 2005, 33:1897-1902.

15. Dubois MJ, De Backer D, Creteur J, Anane S, Vincent JL: Effect of vasopressin on sublingual microcirculation in a patient with distributive shock. Intensive Care Med 2003, 29:1020-1023.

16. Dunser MW, Mayr AJ, Ulmer H, Knotzer H, Sumann G, Pajk W, Friesenecker B, Hasibeder WR: Arginine vasopressin in advanced vasodilatory shock: a prospective, randomized, controlled study. Circulation 2003, 107:2313-2319.

17. lijima $T$, Oguchi $T$, Kashimoto $S$ : Does vasopressin infusion improve the outcome of severe septic-shock without any adverse effects? Anesthesiology 2003, 98:793. author reply 793.

18. Shelly MP, Greatorex R, Calne RY, Park GR: The physiological effects of vasopressin when used to control intra-abdominal bleeding. Intensive Care Medicine 1988, 14:526-531.

19. Boyle WASL 3rd: Direct cardiac effects of vasopressin and their reversal by a vascular antagonist. Am J Physiol 1986, 251:H734-741.

20. Zenteno-Savin T, Sada-Ovalle I, Ceballos G, Rubio R: Effects of arginine vasopressin in the heart are mediated by specific intravascular endothelial receptors. Eur J Pharmacol 2000, 410:15-23.

21. Cheng CP, Igarashi Y, Klopfenstein HS, Applegate RJ, Shihabi Z, Little WC: Effect of vasopressin on left ventricular performance. Am J Physiol 1993, 264:H53-60.

22. Wilson MF, Brackett DJ, Archer LT, Hinshaw LB: Mechanisms of impaired cardiac function by vasopressin. Ann Surg 1980, 191:494-500.

23. Oikawa R, Nasa Y, Ishii R, Kuwaki T, Tanoue A, Tsujimoto G, Takeo $S$ : Vasopressin $\mathrm{V} 1 \mathrm{~A}$ receptor enhances baroreflex via the central component of the reflex arc. Eur J Pharmacol 2007, 558:144-150.

24. Luk J, Ajaelo I, Wong V, Wong J, Chang D, Chou L, Reid IA: Role of $\mathrm{V} 1$ receptors in the action of vasopressin on the baroreflex control of heart rate. American Journal of Physiology 1993, 265:R524-529.

25. Weig HJ, Laugwitz KL, Moretti A, Kronsbein K, Stadele C, Bruning S, Seyfarth M, Brill T, Schomig A, Ungerer M: Enhanced cardiac contractility after gene transfer of $\mathbf{V} 2$ vasopressin receptors in vivo by ultrasound-guided injection or transcoronary delivery. Circulation 2000, 101:1578-1585.

26. Laugwitz KL, Ungerer $M$, Schoneberg $T$, Weig $H J$, Kronsbein $K$, Moretti A, Hoffmann K, Seyfarth M, Schultz G, Schomig A: Adenoviral gene transfer of the human $\mathbf{V} 2$ vasopressin receptor improves contractile force of rat cardiomyocytes. Circulation 1999, 99:925-933.

27. Thibonnier M, Conarty DM, Preston JA, Plesnicher CL, Dweik RA Erzurum SC: Human vascular endothelial cells express oxytocin receptors. Endocrinology 1999, 140:1301-1309.

28. D'Souza SP, Davis M, Baxter GF: Autocrine and paracrine actions of natriuretic peptides in the heart. Pharmacol Ther 2004, 101:113-129.

29. Gutkowska J, Jankowski M, Mukaddam-Daher S, McCann SM: Oxytocin is a cardiovascular hormone. Braz $J$ Med Biol Res 2000, 33:625-633.

30. Luckner G, Dunser MW, Jochberger S, Mayr VD, Wenzel V, Ulmer $H$, Schmid S, Knotzer H, Pajk W, Hasibeder W, Mayr AJ, Friesenecker B: Arginine vasopressin in $\mathbf{3 1 6}$ patients with advanced vasodilatory shock. Crit Care Med 2005, 33:2659-2666.

31. Holmes CL, Walley KR, Chittock DR, Lehman T, Russell JA: The effects of vasopressin on hemodynamics and renal function in severe septic shock: a case series. Intensive Care Med 2001 27:1416-1421.

32. Jolly S, Newton G, Horlick E, Seidelin PH, Ross HJ, Husain M, Dzavik $\mathrm{V}$ : Effect of vasopressin on hemodynamics in patients with refractory cardiogenic shock complicating acute myocardial infarction. Am J Cardiol 2005, 96:1617-1620.

33. Holmes $\mathrm{CL}$, Walley KR: Arginine vasopressin in the treatment of vasodilatory septic shock. Best Pract Res Clin Anaesthesiol 2008, 22:275-286.

34. Yasujima M, Abe K, Tanno M, Omata K, Kasai Y, Sato M, Kimura T, Yoshinaga K: Decreased urinary active and inactive kallikrein by chronic infusion of vasopressin in conscious rats. Tohoku Exp Med 1985, 145:215-222. 
35. Leclerc F, Walter-Nicolet E, Leteurtre S, Noizet O, Sadik A, Cremer $\mathrm{R}$, Fourier C: Admission plasma vasopressin levels in children with meningococcal septic shock. Intensive Care Med 2003, 29:1339-1344.

36. Michael LH, Entman ML, Hartley CJ, Youker KA, Zhu J, Hall SR, Hawkins HK, Berens K, Ballantyne CM: Myocardial ischemia and reperfusion: a murine model. Am J Physiol 1995, 269:H2147-2154.

37. Landry DW, Levin HR, Gallant EM, Ashton RC Jr, Seo S, D'Alessandro $\mathrm{D}, \mathrm{Oz} \mathrm{MC}$, Oliver JA: Vasopressin deficiency contributes to the vasodilation of septic shock. Circulation 1997, 95:1122-1125.

38. Gold J, Cullinane S, Chen J, Seo S, Oz MC, Oliver JA, Landry DW: Vasopressin in the treatment of milrinone-induced hypotension in severe heart failure. Am J Cardiol 2000, 85:506-508. A511.

39. Chen JM, Cullinane S, Spanier TB, Artrip JH, John R, Edwards NM, $\mathrm{Oz} \mathrm{MC}$, Landry DW: Vasopressin deficiency and pressor hypersensitivity in hemodynamically unstable organ donors. Circulation 1999, 100:II244-246.

40. Kelly KJ, Stang JM, Mekhjian HS: Vasopressin provocation of ventricular dysrhythmia. Ann Intern Med 1980, 92:205-206.

41. Klein GJ: Vasopressin, "torsades de pointes," and OT syndrome. Ann Intern Med 1980, 93:511-512.

42. Fitz JD: Vasopressin induction of ventricular ectopy. Arch Intern Med 1982, 142:644.

43. Solanki P, Chawla A, Garg R, Gupta R, Jain M, Sarin SK: Beneficial effects of terlipressin in hepatorenal syndrome: a prospective, randomized placebo-controlled clinical trial. J Gastroenterol Hepatol 2003, 18:152-156.

44. Urge J, Sincl F, Prochazka V, Urbanek K: Terlipressin-induced ventricular arrhythmia. Scand J Gastroenterol 2008, 43:1145-1148

45. Hobo R, Netsu S, Koyasu Y, Tsutsumi O: Bradycardia and cardiac arrest caused by intramyometrial injection of vasopressin during a laparoscopically assisted myomectomy. Obstet Gynecol 2009, 113:484-486.

46. Marban E: The surprising role of vascular K(ATP) channels in vasospastic angina. J Clin Invest 2002, 110:153-154. 